\title{
Electrical Model of an Implantable Epimysial Electrode for EMG
}

\author{
Joel Flores ${ }^{1}$, Patricia Lorena Ramírez ${ }^{2}$, Rita Trinidad Rodríguez ${ }^{3}$ \\ Professor, Communications and Electronic Engineering Department (ICE), ESIME-ZAC, IPN, Mexico City, Mexico ${ }^{1-3}$
}

Abstract: This paper presents the development of an electrical model for an implantable electrode that allows the detection of the most stable and precise electromyography signal (EMG) directly on a skeletal muscle in a chronic way.

Keywords: Implantable epimysial electrode, electrical activity of a skeletal muscle, electromyography (EMG), electrical model of an implantable electrode.

\section{INTRODUCTION}

The development of this type of implantable electrodes has focused on the area of chronic nerve stimulation $[10,12,13]$ and on the functional stimulation of paralyzed or weak muscles $[11,14]$. The implantable electrodes that have been developed mainly are of the cuff type (on the nerve), epimysial (on nerve and muscle) and intramuscular; as shown in Fig. 1.

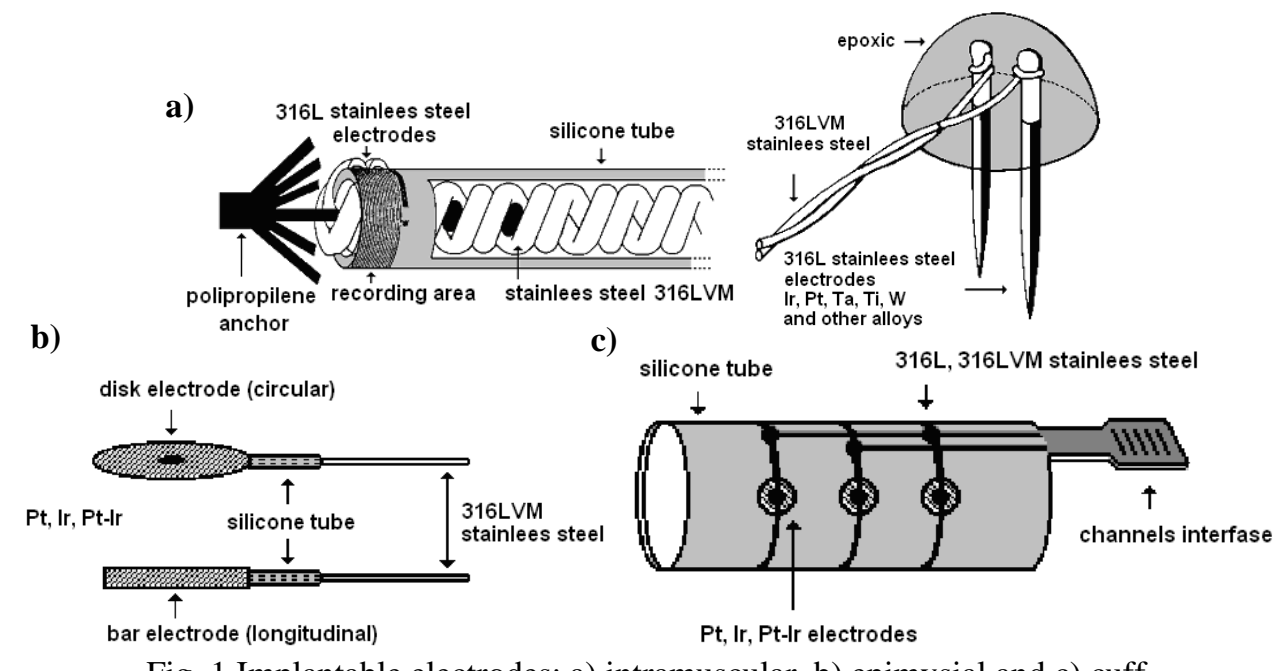

Fig. 1 Implantable electrodes: a) intramuscular, b) epimysial and c) cuff

For the particular case of the recording of an electromyography (EMG) or myoelectric signal with implantable electrodes, the attention has focused on obtaining the signals produced by a few muscle fibers belonging to mammalian muscles. Very limited information has been published on the recording with electrodes of signals produced by most of the motor units of a skeletal muscle. Implantable electrodes were developed because traditional surface recording techniques (for the skin) and insertion or percutaneous electrodes (wire or needle), do not just in situ monitoring for long periods of time $[2,3]$ without the stability and signal reliability is compromised. This long-term recording is used for the control of myoelectric prosthesis $[4,5,6,7,8,9]$ where the stable and reliable recording of the signals of the majority of the motor units in a muscle is an indispensable condition for the proper identification of the EMG signal. Surface electromyography has been used to achieve this control with moderate success.

This work focuses on the development of implantable epimysial electrodes that, applied to chronic and in situ monitoring of the electrical activity of most of the motor units of a skeletal muscle, help to reduce or avoid the problem related to use surface and percutaneous electromyography. On the other hand, having an electrical model provides information on the behaviour of the impedance of the implanted electrodes, without having to subsequently resort to a surgical procedure for the implantation, and thus preventing the animal model from damaging or rejecting the implanted electrodes under study. Excessive disturbance of the animal model is also avoided, and consequently the path of research on implantable telemetry systems is shortened. 


\title{
International Journal of Advanced Research in Computer and Communication Engineering
}

\author{
Vol. 9, Issue 12, December 2020
}

\section{DOI 10.17148/IJARCCE.2020.91201}

\section{DESCRIPTION}

The criteria for the construction of the implantable epimysial electrode are established in terms of design requirements (electrode configuration involving size, shape and distance between electrode surfaces) and design elements (selection of materials). Three different structures were made for the implantable electrodes: a) multipolar flat rectangular type electrodes, b) multipolar round tubular type electrodes and c) bipolar flat rectangular type electrodes; some of them with or without reference electrode. Names are assigned based on the configuration and shape of the surface on which the sensor elements are mounted. Fig. 2 shows the three types of structures proposed for epimysial electrodes.

These epimysial electrodes must allow differential recording: bipolar type, consisting of two electrodes placed on the muscle of interest and a third (reference) electrode placed on an adjacent muscle; of the multipolar type, with several electrodes placed on the muscle of interest. These two types of recording are considered as the greatest amount of information is desired from the EMG signal. Through the percutaneous connector, a means of communication is established between the biological environment and the outside, which allows to follow the evolution of the impedance of the electrode and to record the EMG signal. It also allows you to check the integrity and correct functioning of the electrode during the implantation procedure.

The epimysial electrode was implanted in an animal model (young New Zealand rabbit) between the cervical and thoracic portions of the trapezius muscle. This is because it is a large muscle that is difficult for the animal to access, thus preventing the electrode from being pulled out once the animal is bothered by postoperative symptoms.

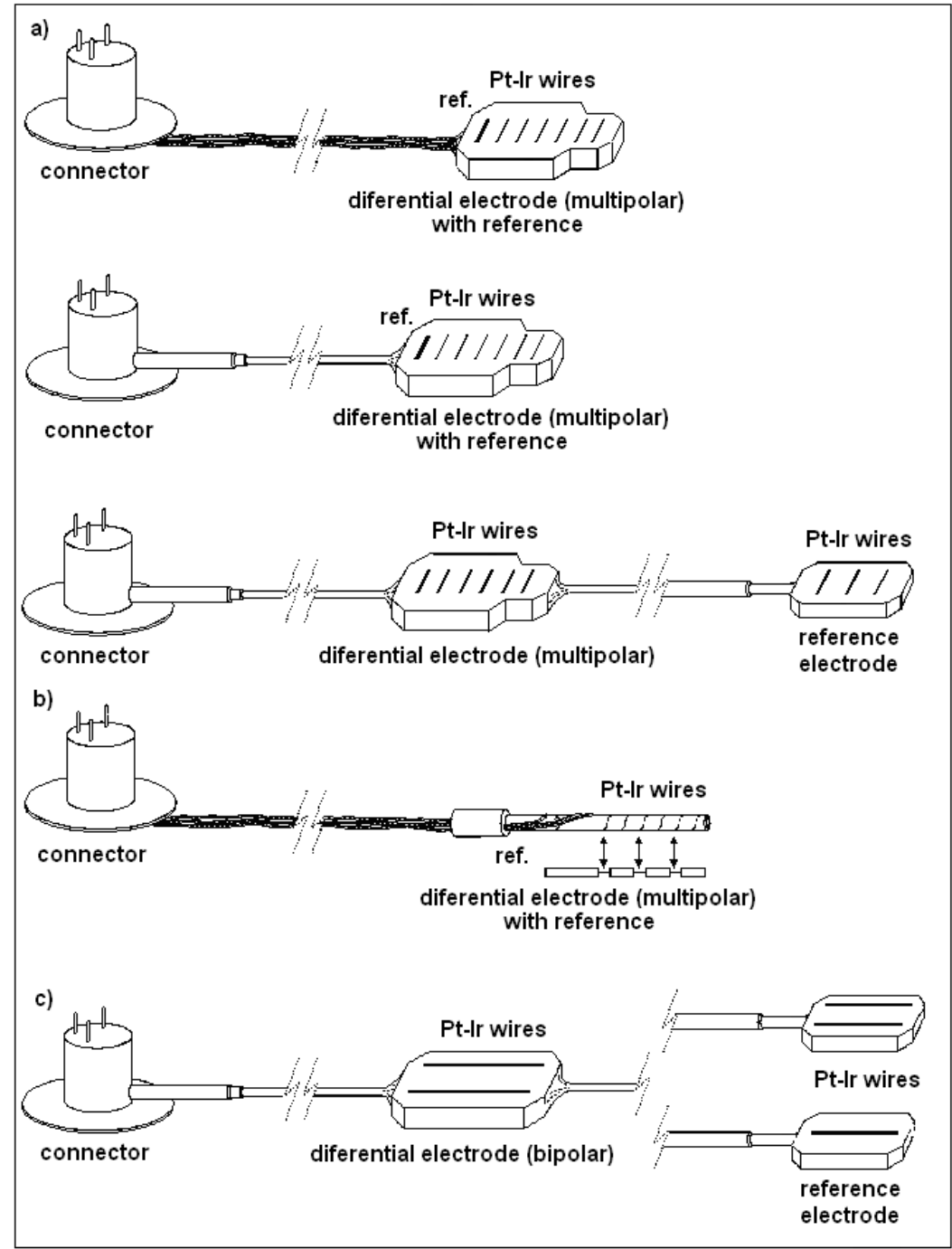

Fig. 2 Three structures proposed for the implantable epimysial electrode:

a) flat rectangular multipolar, b) round tubular multipolar and c) flat rectangular bipolar 


\title{
International Journal of Advanced Research in Computer and Communication Engineering
}

\author{
Vol. 9, Issue 12, December 2020
}

\section{DOI 10.17148/IJARCCE.2020.91201}

Once epimysial electrodes have been developed and implanted, they need to be evaluated in three main aspects: mechanical, electrical and biological. These parameters are involved in obtaining a stable and reliable detection of electrical activity produced by skeletal muscle, in situ and chronically.

This work focuses on the electrical aspect, which includes the evaluation of the electrical parameters of the electrode. These parameters determine its behaviour during the implantation, through the impedance and EMG signal of the implanted epimysial electrode. This is due to the fact that the recording of the impedance as a function of time since the implantation gives an idea of the stability of the impedance as an indicator of the maturity period of the implanted electrode. This is because this parameter is an indicator of the growth of fibrous tissue around the electrode. Likewise, the impedance, as a function of frequency, provides a notion of the responsiveness to the EMG, based on a comparison of the results under saline conditions, at the time of implantation and in the last weeks of registration. An electrical model of the electrode is thus obtained to simulate its response as a circuit element, providing essential information for the design of stimulation and recording systems.

Changes in the magnitude of impedance can be caused by changes in fibrous tissue, tissue fluid, muscle and the electrode itself, during the implantation period. Major changes in impedance are present during the swelling, coagulation and hemolysis stages. If the impedance remains constant over time, it may be an indication that the adaptation of the implanted electrode in the biological environment has been achieved and, consequently, it becomes stable. Then it can be said that stable and reliable physiologically tolerable or mature electrode, being appropriate for the chronic recording of EMG. To measure the impedances of the implanted electrodes, a resistive circuit was applied, as shown in Fig. 3.

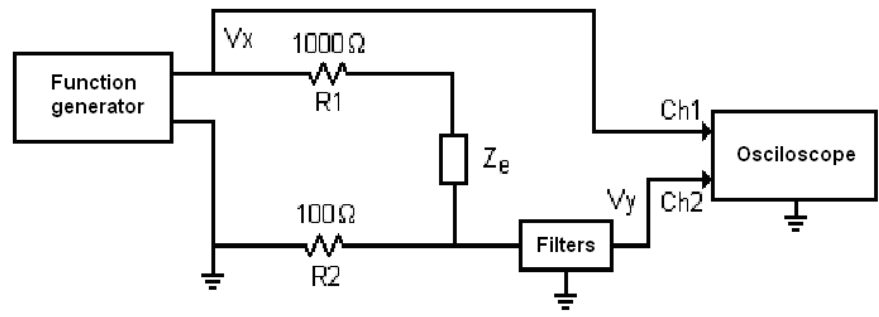

Fig. 3 Circuit applied to measure the impedance of the implanted electrodes

If: $V_{x}=2.5 \sin \omega t$ and: $V_{y}=V_{y} \sin (\omega t+\theta)$

Current is given by:

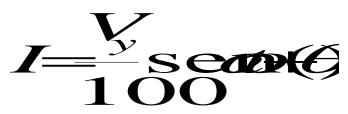

\section{a 1 iesesea}

where: $\mathrm{V}_{\mathrm{x}}=$ peak voltage from the generator

$$
\begin{aligned}
V_{y} & =\text { peak voltage at } R_{100} \\
f & =\text { natural frequency in } \mathrm{Hz} \\
t_{R} & =\text { delay time in } \mathrm{ms} \\
t_{\mathrm{RF}} & =\text { delay time produced by the filters in } \mathrm{ms} \\
\omega & =\text { angular frequency in } \mathrm{rad} / \mathrm{s}
\end{aligned}
$$

Clearing for $\mathrm{Z}_{\mathrm{e}}$ :
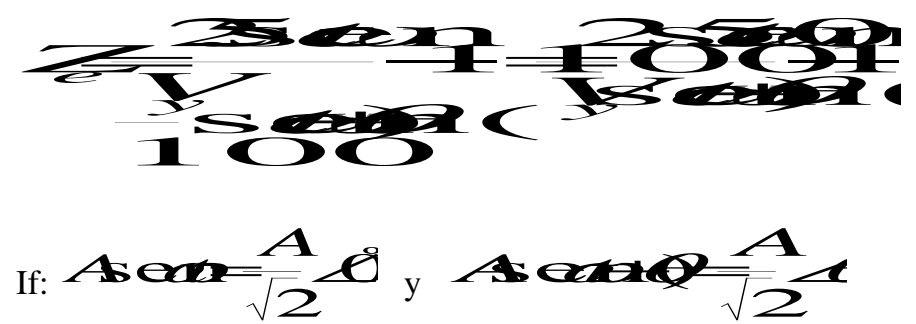

Thus:

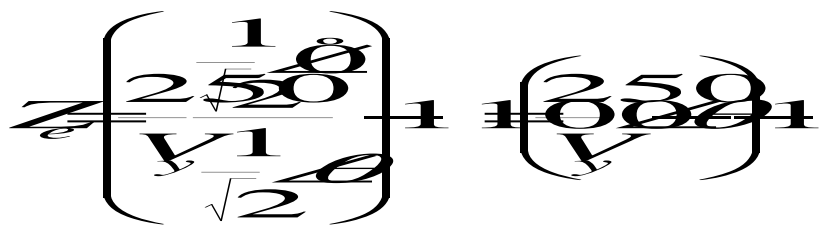


As: $\mathrm{k}\llcorner\alpha=\mathrm{k} \cos (\alpha)+\mathrm{jk} \sin (\alpha)$

So: $\mathrm{Re}=\mathrm{k} \cos (\alpha)$ and: $\operatorname{Im}=\mathrm{k} \sin (\alpha)$
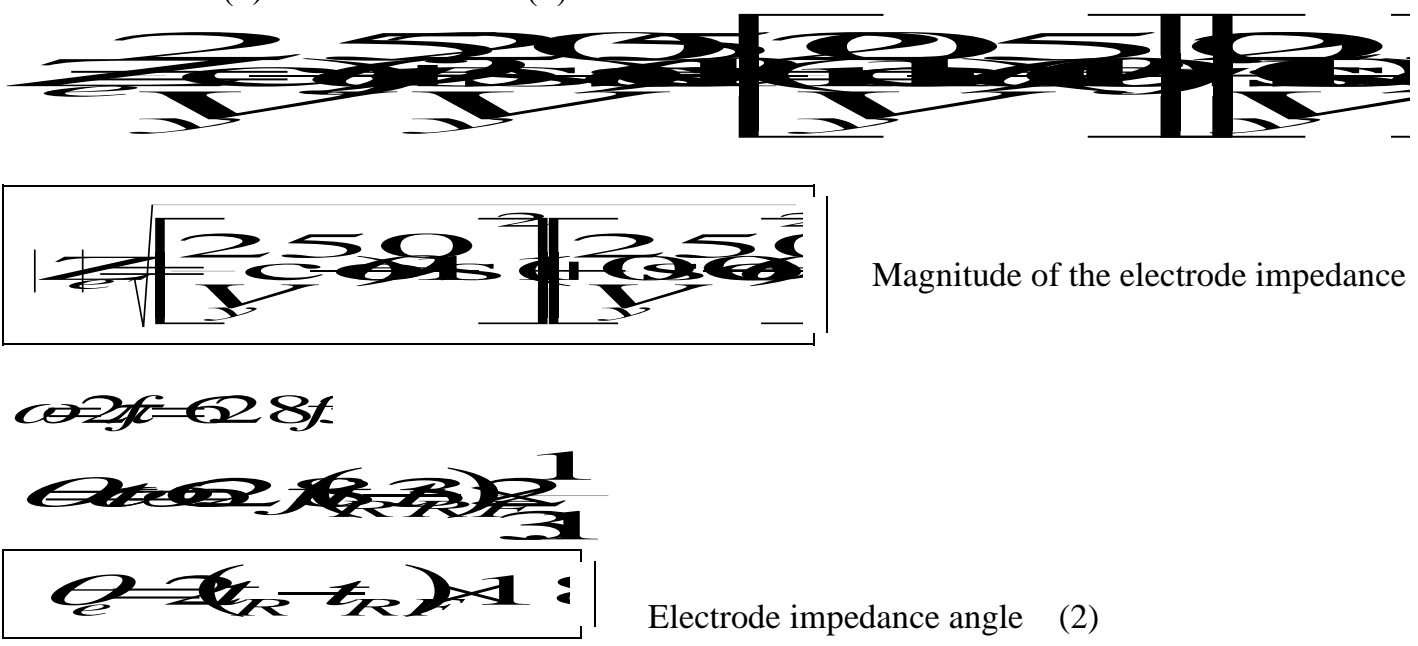

Electrode impedance angle

Equations 3 and 4 are used to calculate the real and imaginary parts of the electrode impedance:

$$
R=Z \text { GCO }
$$

$\mathrm{y}$

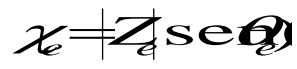

The input voltage signal, with amplitude of $5 \mathrm{Vpp}$ (peak-to-peak voltage) and variable frequency, is produced by the function generator. This voltage ( $\mathrm{Vx})$ is measured and adjusted, and its waveform is viewed on the oscilloscope through channel 1. This signal will serve as the reference waveform. Current will flow through the entire circuit and a voltage drop will appear across the $100 \Omega$ resistor terminals. This voltage drop is sent through the filter and its output is measured and viewed on channel 2 of the oscilloscope. This signal appears distorted, noisy, with reduced amplitude and delayed. These characteristics arise because other signals are added through the electrode. The reduced amplitude is due to the voltage drop across resistor $\mathrm{R}_{2}$, since $\mathrm{R}_{2}<\mathrm{R}_{1}$. The delay is caused by the filters and capacitive components in the electrode from their contact with the muscle.

The impedance was measured at $0.5,1,10,100,1000$ y $5000 \mathrm{~Hz}$ under different conditions: a) before implantation with the electrodes immersed in isotonic saline solution (unfiltered); b) at the time of implantation and c) during the period of time that the electrode remained implanted in the animal model, daily. The magnitude and phase angle of the impedance of the electrodes were calculated, for each frequency value, considering the peak-to-peak voltage at the filter output and the delay time between the reference voltage and filter output.

\section{III.RESULTS}

To determine the maturity of the implanted epimysial electrode, the magnitude of the impedance was evaluated daily. This evaluation lasted as long as the 6 electrodes remained within the animal model (bipolar: 1, 2, 3, 4; multipolar: 1 and 2). The averages of the impedance magnitudes obtained per week were calculated for each frequency, considering 5 days of continuous recording. A second degree polynomial was fitted to the results of the averages. The fitted curve is shown in Fig. 4 as a solid line.

The electrical model was obtained by comparison, by trial and error, the frequency response of the electrode in the last weeks of impedance recording, with the response obtained from computer simulations. Initially, the model consisted of two pairs of $\mathrm{RC}$ branches connected in parallel $\left(\mathrm{R}_{1} \mathrm{C}_{1}\right.$ and $\left.\mathrm{R}_{2} \mathrm{C}_{2}\right)$, in series with a resistor $\mathrm{R}\left(\mathrm{R}_{3}\right.$ and $\left.\mathrm{R}_{4}\right)$. This structure was later modified to indicate that an RC circuit is distributed over two electrode-electrolyte interfaces. 
DOI 10.17148/IJARCCE.2020.91201
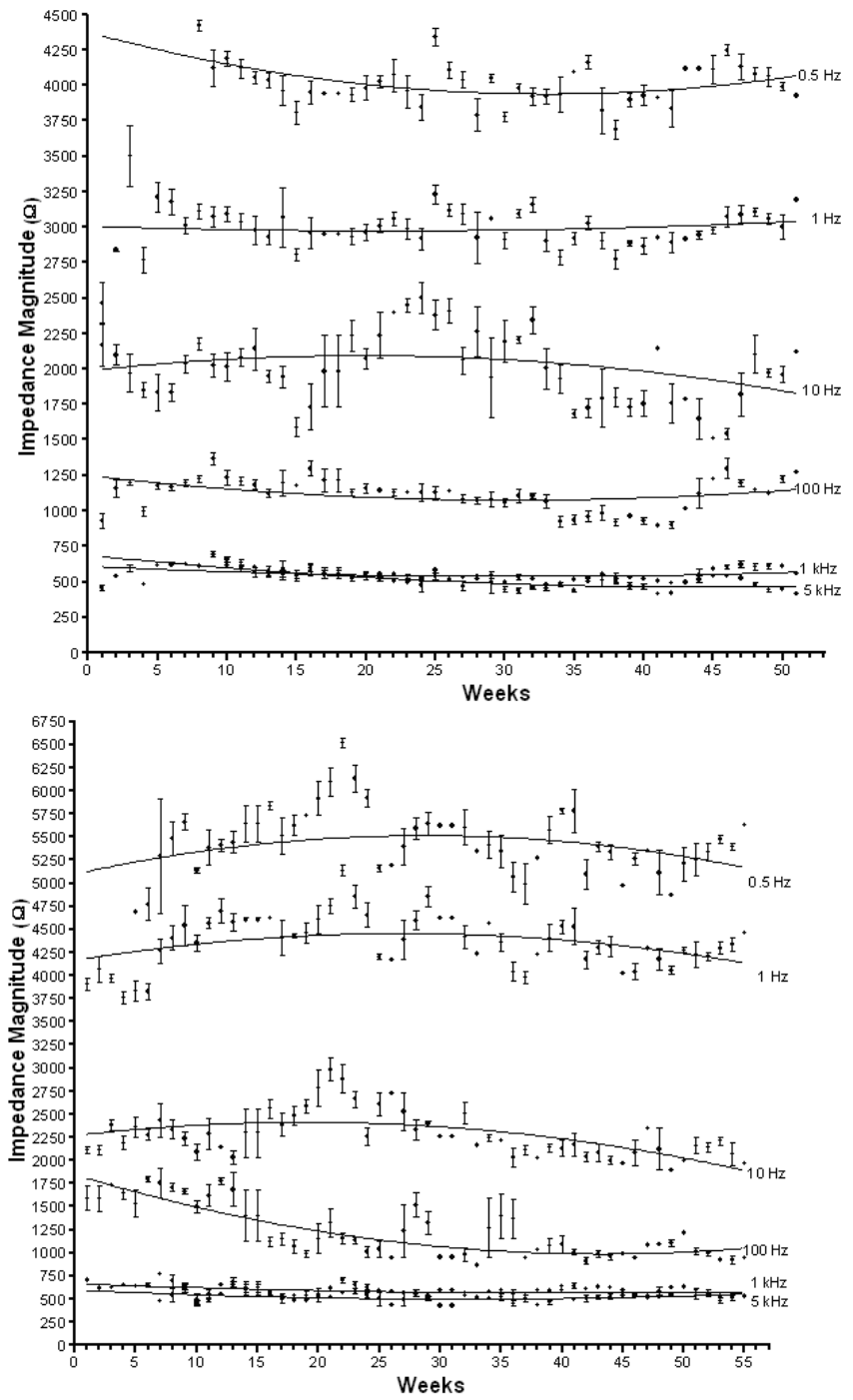

Fig. 4 Curve fitting of the two most representative types of electrodes: Bipolar 1 and Multipolar 1, respectively Finally, Fig. 5 shows the proposed electrical model.

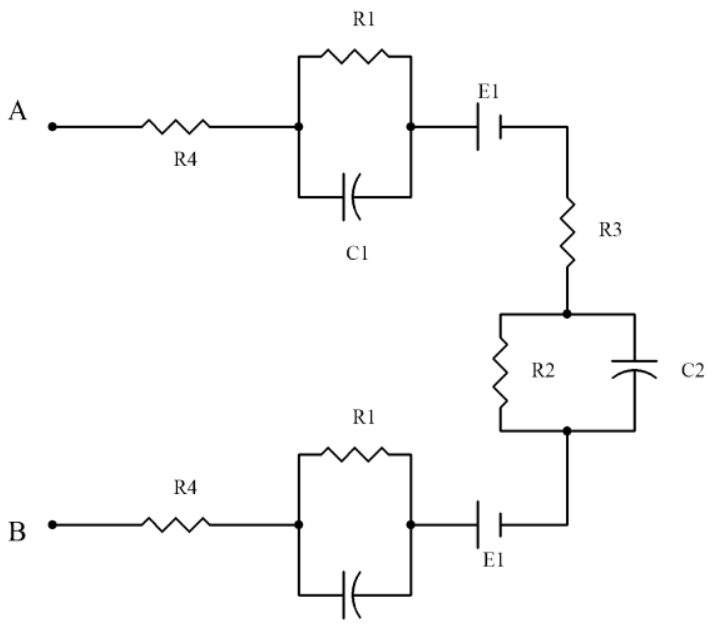

$\mathrm{C} 1$

Fig. 5. Electrical model of the implanted epimysial electrodes 
Resistor $\mathrm{R}_{4}$ represents the resistance of the junction between the Pt-Ir and stainless steel wires (the electrode conductors). The parallel connection of $\mathrm{R}_{1}$ and $\mathrm{C}_{1}$ represents the charge distribution and the Helmholtz double layer at the electrodeelectrolyte interface, respectively. The double layer formed when the electrode and the electrolyte (tissue fluid) come into contact generates a voltage $\mathrm{E}_{1}$, known as half-cell potential $[1,15,16,17,18]$. On the other side, the parallel branch $\mathrm{R}_{2}$ and $\mathrm{C}_{2}$ represents the detection area formed in between the electrodes. Capacitance can be attributed to the surface of the electrode, the separation between the electrodes, and the tissue fluid accumulated between them. The resistance is attributed to the accumulated muscle tissue between both electrodes. $\mathrm{R}_{3}$ corresponds to the muscular and fibrous tissue that grows around the electrodes. Table 1 shows the results obtained for these elements of the circuit from the frequency response of the models of each of the electrodes.

TABLE 1 MAGNITUDES OF CIRCUIT ELEMENTS FOR EACH OF THE IMPLANTED EPIMYSIAL ELECTRODES

\begin{tabular}{|l|c|c|c|c|c|c|}
\hline \multirow{2}{*}{\multicolumn{1}{c|}{ Electrode type }} & \multicolumn{7}{c|}{ Circuit elements } \\
\cline { 2 - 7 } & $\mathbf{R}_{\mathbf{1}}$ & $\mathbf{C}_{\mathbf{1}}$ & $\mathbf{R}_{\mathbf{2}}$ & $\mathbf{C}_{\mathbf{2}}$ & $\mathbf{R}_{\mathbf{3}}$ & $\mathbf{R}_{\mathbf{4}}$ \\
\hline Model 1 (Bipolar 1) & $1.95 \mathrm{k} \square$ & $104 \mu \mathrm{F}$ & $540 \square$ & $0.47 \mu \mathrm{F}$ & $353.2 \square$ & $8.4 \square$ \\
\hline Model 2 (Bipolar 2) & $1.75 \mathrm{k} \square$ & $112 \mu \mathrm{F}$ & $340 \square$ & $1 \mu \mathrm{F}$ & $423.2 \square$ & $8.4 \square$ \\
\hline Model 3 (Bipolar 3) & $1.46 \mathrm{k} \square$ & $123 \mu \mathrm{F}$ & $280 \square$ & $1.2 \mu \mathrm{F}$ & $241.4 \square$ & $9.3 \square$ \\
\hline Model 4 (Bipolar 4) & $1.7 \mathrm{k} \square$ & $128 \mu \mathrm{F}$ & $480 \square$ & $0.36 \mu \mathrm{F}$ & $191.4 \square$ & $9.3 \square$ \\
\hline Model 5 (Multipolar 1) & $2.7 \mathrm{k} \square$ & $64 \mu \mathrm{F}$ & $400 \square$ & $2.2 \mu \mathrm{F}$ & $414.6 \square$ & $7.7 \square$ \\
\hline Model 6 (Multipolar 2) & $2.35 \mathrm{k} \square$ & $73.4 \mu \mathrm{F}$ & $560 \square$ & $0.49 \mu \mathrm{F}$ & $224.6 \square$ & $7.7 \square$ \\
\hline
\end{tabular}

From these circuit elements, the magnitude of the total impedance of the electrical model between terminals A and B can be calculated. The results are shown in Table 2 for the two most representative types of electrodes.

TABLE 2. MAGNITUDES OF IMPEDANCE AT DIFFERENT FREQUENCIES FOR THE TWO MOST REPRESENTATIVE TYPES OF ELECTRODES

\begin{tabular}{|c|c|c|c|c|c|c|c|}
\hline \multirow{2}{*}{$\begin{array}{l}\text { Electrode } \\
\text { type }\end{array}$} & \multicolumn{7}{|c|}{ Impedance magnitude $(\square)$} \\
\hline & Calculations for: & $0.5 \mathrm{~Hz}$ & $1 \mathrm{~Hz}$ & $10 \mathrm{~Hz}$ & $100 \mathrm{~Hz}$ & $1 \mathrm{kHz}$ & $5 \mathrm{kHz}$ \\
\hline \multirow{5}{*}{ Bipolar 1} & Saline solution & 5844.444 & 4754.234 & 1706.911 & 564.482 & 378.579 & 308.974 \\
\hline & $\begin{array}{l}\text { At the time of } \\
\text { implantation }\end{array}$ & & 3983.338 & 2096.606 & 1401.029 & 665.620 & \\
\hline & $\begin{array}{l}\text { Last month of } \\
\text { implant } \\
\text { (4 weeks) }\end{array}$ & 4013.836 & 3090.014 & 2039.679 & 1192.587 & 595.473 & 446.037 \\
\hline & Electric model & 4086.176 & 3055.151 & 984.737 & 904.138 & 577.485 & 384.3 \\
\hline & $\begin{array}{l}\text { Matching } \\
\text { impedances }\end{array}$ & 4013.835 & 3090.013 & 2039.578 & 1192.586 & 595.472 & 446.036 \\
\hline \multirow{5}{*}{ Multipolar 1} & Saline solution & 4782.353 & 4028.287 & 1464.187 & 562.377 & 323.490 & 283.450 \\
\hline & $\begin{array}{l}\text { At the time of } \\
\text { implantation }\end{array}$ & & 4822.771 & 2835.760 & 1533.803 & 718.447 & \\
\hline & $\begin{array}{l}\text { Last month of } \\
\text { implant } \\
(4 \text { weeks })\end{array}$ & 5458.404 & 4325.299 & 2098.111 & 943.895 & 535.181 & 522.114 \\
\hline & Electric model & 5489.985 & 4265.938 & 1014.735 & 768.7 & 448.986 & 430.8 \\
\hline & $\begin{array}{l}\text { Matching } \\
\text { impedances }\end{array}$ & 5458.403 & 4325.297 & 2098.110 & 943.894 & 535.180 & 522.113 \\
\hline
\end{tabular}

If the Laplace transform is applied to the electrical model of the implanted epimysial electrode to obtain the impedance $\mathrm{Z}(\mathrm{s})$ of the two-terminal structure, equation 5 is obtained.

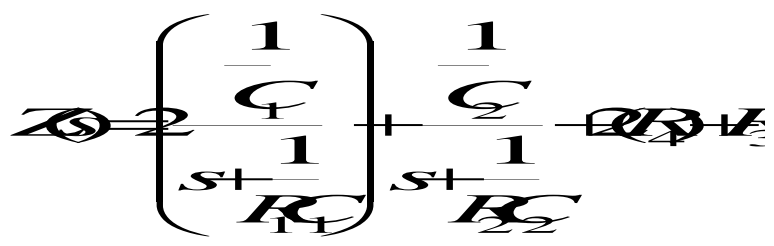




\title{
International Journal of Advanced Research in Computer and Communication Engineering
}

\author{
Vol. 9, Issue 12, December 2020
}

\section{DOI 10.17148/IJARCCE.2020.91201}

To determine the real and imaginary components of the impedance of the equivalent circuit, $s=j \omega$ is substituted into equation 5. The rectangular form of $\mathrm{Z}(\mathrm{j} \omega)$ is thus obtained.

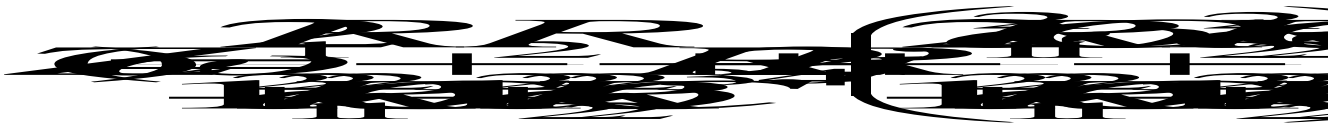

The behaviour of the impedance magnitude can be established considering equation 6, the equivalent circuit in Fig. 5 and the graphs in Fig. 4. For the case of high frequencies, it can be seen in Fig. 4 that the magnitude of the resistance remains approximately constant regardless of frequency $(1$ and $5 \mathrm{KHz})$. For the model in Fig. 5 , the capacitive reactance approaches zero as the frequency of the input signal between points $\mathrm{A}$ and $\mathrm{B}$ increases, producing a magnitude of impedance equal to $2 \mathrm{R}_{4}+\mathrm{R}_{3}$. It can be concluded that the behaviour magnitude impedance is mainly resistive. For the case of low frequencies, the graphs in Fig. 4 show that the impedance is a function of the frequency of the input signal, suggesting a capacitive behaviour in the impedance of the implantable electrodes.

\section{IV.CONCLUSION}

The maturity period of the implanted epimysial electrodes was determined as a function of the magnitude of the impedance, when it reached its stage of stability. Periods of 15 to 20 weeks were obtained for bipolar electrodes and 15 to 35 weeks for multipolar electrodes.

Using the electrical model developed, a resistive and capacitive behaviour of the implanted epimysial electrodes was verified. The capacitive effect is pronounced at $0.5,1$ and $10 \mathrm{~Hz}$, and the resistive effect at 100, 1000 and $5000 \mathrm{~Hz}$. These effects test the instability of the impedance at low frequencies and its stability at high frequency, as well as the definition of the elements of the circuit (resistors and capacitors) that form the electrical structure between electrode and muscle.

\section{REFERENCES}

[1] L. A. Geddes and L. E. Baker, Principles of applied biomedical instrumentation, Ed. John Wiley \& Sons, New York, 1989.

[2] D. B. McCreery, W. F. Agnew and J. McHardy, "Electrical characteristics of chronically implanted platinum-iridium electrodes", IEEE Trans. BME-34, pp. 664-668, Sep. 1987.

[3] J. V. Basmajian and C. J. De Luca, Muscles alive. Their functions revealed by electromyography, Ed. Williams and Wilkins, Baltimore, 1985.

[4] C. J. De Luca, "Control of upper-limb prostheses: a case for neuroelectric control", Journal of Medical Engineering and Technology, Vol. 2, No. 2, pp. 57-59, Mar. 1978.

[5] R. N. Scott and P. A. Parker, "Myoelectric prostheses: state of the art", Journal of Medical Engineering and Technology, Vol. 12, No. 4, pp. 143151, Aug. 1988.

[6] P. A. O’Neill, E. L. Morin and R. N. Scott, "Myoelectric signal characteristics from muscles in residual upper limbs", IEEE Trans. Rehabilitation Engineering, Vol. 2, pp. 266-269, Dec. 1994.

[7] C. J. Abul-Hal and N. Hogan, "Functional assessment of control systems for cybernetic elbow prostheses-Part I and II", IEEE Trans. BME-37, pp. 1025-1047, Nov. 1990.

[8] G. N. Saridis and T. P. Gootee, "EMG pattern analysis and classification for a prosthetic arm”, IEEE Trans. BME-29, pp. 403-411, Jun. 1982.

[9] B. Hudgins, P. Parker and R. N. Scott, “A new strategy for multifunction myoelectric control”, IEEE Trans. BME-40, pp. 82-93, Jan. 1993.

[10] J. T. Mortimer, J. D. Sweeney, D. R. Bodner and A. S. Ferguson, "An implantable cuff electrode for collision block of pudendal nerve motor activity", IEEE Engineering in Medicine \& Biology Society 10 th Annual International Conference, 1988.

[11] W. D. Memberg, P. H. Peckman, M. W. Keith and M. Gazdik, "A surgically-implanted intramuscular electrode for an implantable neuromuscular stimulation system", IEEE Engineering in Medicine \& Biology Society $11^{\text {th }}$ Annual International Conference, 1989.

[12] (2000) Implantable microsystems for visual and hearing aids. [Online]. Available: http://www.cnm.es/imb/IMB-SP/lneas.htm

[13] A. Jonzon, E. N. Larsson, P. A. Öberg and G. Sedin, "Long-term implantation of platinum electrodes: effects on electrode material and nerve tissue", Med. \& Biol. Eng. \& Comput, Vol. 26, pp. 624-627, Nov. 1988.

[14] J. M. Akers, B. T. Smith and R. R. Betz, "Implantable electrode lead in a growing limb", IEEE Trans. Rehabilitation Engineering, Vol. 7, pp. 3545, Mar. 1999.

[15] S. Adreassen and A. Rosenfalck, "Recording from a single motor unit during strong effort", IEEE Trans. BME-25, pp. 501-508, Nov. 1978.

[16] M. E. Valentinuzzi, "Bioelectrical impedance techniques in medicine. Part I. Bio-impedance measurement", Critical Reviews in Biomedical Engineering, Vol. 24, pp. 223-255, 1996.

[17] L. A. Geddes, "Historical evolution of circuit models for the electrode-electrolyte interface", Annals of Biomedical Engineering, Vol. 25, pp. 1$14,1997$.

[18] T. Ragheb and L. A. Geddes, “Electrical properties of metallic electrodes”, Med. \& Biol. Eng. \& Comput., Vol. 28, pp. 182-186, Mar. 1990.

\section{BIOGRAPHY}

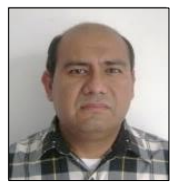

Joel Flores Martínez received his B.Sc. in electronics and communications engineering from ESIME Zacatenco IPN, Mexico, in 1997 and M.Sc. degree in Bioelectronics from CINVESTAV IPN, Mexico in 2000. Currently he is a Professor at the Department of Electronics and Communications engineering in ESIME Zacatenco. His research interests are in acoustics and biomedical engineering. 
International Journal of Advanced Research in Computer and Communication Engineering

Vol. 9, Issue 12, December 2020

DOI 10.17148/IJARCCE.2020.91201

Patricia Lorena Ramírez Rangel received her B.Sc. in electronics and communications engineering from ESIME Zacatenco IPN, Mexico, in 1997. Currently she is a teacher at the Department of Electronics and Communications engineering in ESIME Zacatenco. Her research interests are in acoustics.

Rita Trinidad Rodríguez Márquez received her B.Sc. in electric engineering from ESIME Zacatenco IPN, Mexico, in 1995. Currently she is a teacher at the Department of Electronics and Communications engineering in ESIME Zacatenco. Her research interests are in the theory of electrical circuits. 